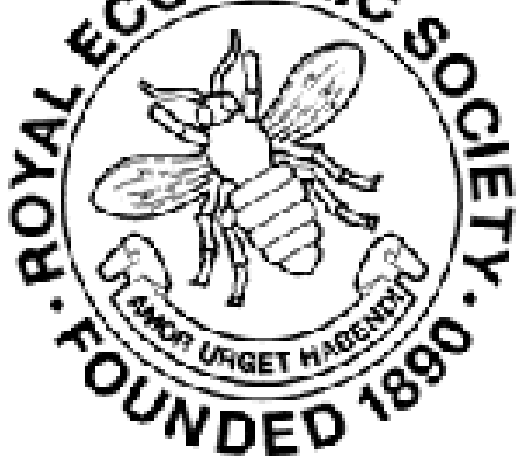

The Historical Basis of English Poor-Law Policy

Author(s): Helen Bosanquet

Source: The Economic Journal, Vol. 20, No. 78 (Jun., 1910), pp. 182-194

Published by: Wiley on behalf of the Royal Economic Society

Stable URL: http://www.jstor.org/stable/2220915

Accessed: 26-06-2016 05:20 UTC

Your use of the JSTOR archive indicates your acceptance of the Terms \& Conditions of Use, available at

http://about.jstor.org/terms

JSTOR is a not-for-profit service that helps scholars, researchers, and students discover, use, and build upon a wide range of content in a trusted digital archive. We use information technology and tools to increase productivity and facilitate new forms of scholarship. For more information about JSTOR, please contact support@jstor.org.

Royal Economic Society, Wiley are collaborating with JSTOR to digitize, preserve and extend access to The Economic Journal 


\section{THE HISTORICAL BASIS OF ENGLISH POOR-LAW POLICY.}

Mr. and Mrs. WebB's “English Poor-Law Policy" ${ }^{1}$ is written in the interests of a well-known propaganda, and aims at showing that the principles and policy advocated by that propaganda are the inevitable outcome of the past. "It is here not a question of whether we approve of this evolution of policy, or of whether we should seek to promote or to resist it, but merely of what exactly it has̀ been, and therefore now is" (p. vi). They express in their Preface their surprise that no such chronological analysis of policy as theirs has ever before been undertaken; and attribute to the difficulty of the undertaking "this general reluctance to work out, from the materials themselves, the Poor-Law history of the last three-quarters of a century." To students of Poor-Law history the surprise will be, we think, at this uncalled-for depreciation of the excellent work of such historians as Sir G. Nicholls, Mr. Mackay, and Sir W. Chance.

The material from which the authors themselves set out to write Poor-Law history consists of the "Statutes, Orders, Circulars, Minutes, Reports, Letters, \&c.," of the Central Authority, together with the manuscript records and letterbooks of a score of Boards of Guardians (p. vii). In defence of previous historians, whose work will certainly not be superseded by this essay, it may be pointed out that Poor-Law history is not, for the most part, made at the Local Government Board; it is not even chronicled there to any great extent. It is made at 600 Boards of Guardians, acting on their own responsibility within the very wide limits prescribed by the Local Government Board, and able to develop policies so opposed to one another as that of Poplar on the one hand and Whitechapel on the other. Hence previous historians have been amply justified in preferring to the mere chronological analysis of Statutes, Orders, Circulars, \&c. (many of which have had little or no effect upon actual

1 English Poor-Law Policy. By Beatrice and Sidney Webb. Longmans, Green and Co. Pp. xiii, 379. 
practice), a method which should bring their readers more into touch with reality.

The Preface also describes at some length, "as an instance of sociological method," the plan upon which the writers dealt with the mass of documentary material which they accumulated. It consisted in employing assistants to copy out "the expressions of policy embodied in each document . . . on loose sheets of paper of even size and shape" (pp. vii, viii). Then the loose sheets were sorted by subjects and arranged chronologically, and from them the history was written. It was no doubt a heavy task, taking some twelve months in all to complete; but whether it is properly to be dignified by the name of a "sociological method" is doubtful. Every student, we suppose, makes notes; and everyone who has made an index is familiar with the dodge of writing his entries on separate slips and then sorting them out. From the point of view of the historian the plan is open to the grave objection that the excerpts are very effectively separated from their context, which may lead to serious errors in interpretation, especially when the person who makes the excerpts is not the person who writes the history. The authors claim to have done their work with "scrupulous accuracy and exhaustiveness" (p. viii).

What is it that the work sets out to prove? It is this: That Poor-Law Policy as based upon the Report of 1834 was originally guided by three Principles; that in 1907 Poor-Law Policy was guided by three new Principles unknown in 1834; and that the Central Authority has in the interval been "reluctantly driven" from the one set of Principles to the other. The final step, of course, is to identify the Principles of 1907 with those of the Minority Report, and to accuse the Majority of ignorant muddling of the two sets. The whole argument is of surpassing ingenuity, but I submit that it does not stand the test of a reference to the original documents.

To disentangle the argument, and at the same time to do justice to its ingenuity, is a task of some difficulty. We may begin by enumerating the two sets of Principles, defining the new ones in the words of their discoverers. Those of 1834 are: (1) The Principle of National Uniformity, i.e., of national uniformity in the treatment of each class of destitute persons. (2) The Principle of Less Eligibility, i.e., that the condition of the pauper should be "less eligible" than that of the lowest grade of independent labourer. (3) The Workhouse System. (Ch. V.) The "New Principles unknown in 1834" are : (1) The Principle of Curative Treatment-"that is, of bringing about in the applicant actual 
physical or mental improvement, so as to render him positively more fit than if he had abstained from applying for relief." (p. 264). (2) The Principle of Universal Provision - "that is, the provision by the State of particular services for all who will accept them, irrespective of 'destitution' or inability to provide the services independently" (p. 267). (3) The Principle of Compulsion, "in the sense of treating an individual in the way that the community deems best, whether he likes it or not" (p. 268).

These, then, are the dramatis persona, and the plot of the story is to show the hero (the Poor-Law Commissioners, alias the Poor-Law Board, alias the Local Government Board, alias the Central Authority) driven reluctantly from the arms of the vicious Principles of 1834 into those of the virtuous Principles of 1907. The story told by the Majority is less dramatic; there is no plot, no hero to speak of, and no victory of virtue over vice. There is only, and perhaps this not really less interesting, the gradual evolution of the policy of 1834 as it adapts itself to the changing conditions of social and industrial life, and utilises the increasing resources of science and experience.

As an illustration of the method upon which the action of the piece is developed, let us take the case of Medical Relief. This is clearly an instance in which the policy of the Local Government Board in 1907 is guided by the Principle of Curative Treatment"that is, of bringing about in the applicant actual physical or mental improvement, so as to render him positively more fit than if he had abstained from applying for relief." What has to be shown is, that the same Principle did not actuate the Commissioners of 1834, and the Poor-Law Board after them. Hence we find it stated that, "When the Commissioners came to sketch out the classification of their proposed workhouse institutions, they did not include anything in the nature of a hospital," and that "This omission of anything in the nature of proposals for indoor relief of the sick becomes the more significant when we notice that the Commissioners do allude with approval to a possible extension of institutional treatment for certain classes of defectives, such as lunatics and blind" (p. 8). On p. 118 we find this statement repeated in a stronger form: "We have shown that the institutional provision for the sick was not so much as mentioned in the Report of 1834." There is an air of proof about "we have shown" which is not justified, for when we turn to the Report of 1834 itself, we find it quite distinctly explained that, of the houses to be assigned to different classes of paupers, one is to be set aside for the sick : "in the workhouse of a single parish 
the rooms appropriated for the use of the sick must often be empty; in a house for the reception of the sick from a number of parishes, the absence of patients from one parish would be met by an influx from another, and a more steady average maintained" (p. 313). Surely one of the slips of paper must have fallen under the table!

We come next to the authors' summary of the policy of the Central Authority in 1847, more especially as incorporated in the General Consolidated Order of that date. In section (X.), "The Workhouse of the General Consolidated Order of 1847," we are told that "Even the sick are almost entirely ignored in the Order of the "Central Authority, and there is the very minimum of recognition of an hospital provision. The policy of the Central Authority at this date, in short, deliberately excluded any use of the workhouse for the curative, reformative, or educational treatment of any class whatsoever" (p. 82). But turn to the Order itself, and what do we find? It provides for the appointment of a Medical Officer and Nurse in each workhouse (Article 153). It orders that every pauper on admission shall be examined by the medical officer, and if labouring under any disease of body or mind be placed in the sick ward or such other ward as the medical officer shall direct (Articles 91 and 92). It instructs the Guardians to consult with the medical officer from time to time, and make such arrangements as they may deem necessary with regard to persons labouring under any disease of body or mind (Article 99). It sets out in detail the duties of medical officer and nurse (Articles 207, 213). It provides that the Visiting Committee shall report to the Guardians their answers to the following questions: "Is regular attendance given by the medical officer? Are the inmates of the sick wards properly tended? Are the nurses efficient? Is there any infectious disease in the workhouse?" (Article 149).

With what justice can an authority which prescribes so carefully provision for the treatment of the sick be accused of deliberately excluding any use of the workhouse for the curative treatment of any class? That many Boards of Guardians failed in their interpretation of these instructions, and that in consequence the actual treatment of the sick was often unsatisfactory, is beyond dispute; but we are here dealing with the policy of the Central Authority as expressed in its Orders, which is another matter. The fact is that the Central Authority has always been in the unhappy position of endeavouring to hold together many thousands of Poor-Law Guardians and their officials to something

No. 78.- -voL. $\mathrm{xx}$. 
like a common policy, while those before cried "Forward!" and those behind cried "Back!"

By their suppression of relevant passages, the authors lead us skilfully up to the dramatic moment in the 'sixties when an inquiry instituted by the Lancet revealed the deficient condition of the workhouse infirmaries. It is represented as the moment of conversion of the Central Authority to the new Principle. "The Central Authority at once accepted the new standpoint. It made no attempt to resist the provision of the necessarily costly institutional treatment for the sick poor, whether or not their ailments were infectious or otherwise dangerous to the public. The progressive improvement of 'the hospital branch of Poor-Law administration,' to use the phrase of the Central Authority itself, which had in the preceding years grown up unawares, was now definitely accepted as an important feature of its policy" (pp. 11920). It is difficult to see how, in face of the articles quoted above from the Order of 1847, the hospital branch of Poor-Law administration can be said to have grown up unawares. What we really have is no sudden conversion to a new Principle unknown in 1834, but a consistent development of the idea of special treatment for the sick ("curative treatment"), of which the germ was present in the special house for the sick indicated in the 1834 Report, which was elaborated in the General Consolidated Order of 1847, and which received great impetus in the movement for hospital reform from 1865 onwards to the present day.

But it is not only in relation to the sick that we find the "Principle of Curative Treatment" is a natural and consistent development from 1834. It is still more obvious in the case of the children that the policy of the Central Authority has always been to bring about "actual physical and mental improvement." From the very first stress was laid on the importance of providing education and training for the children, and the Consolidated Order of 1847 provides for the appointment of a schoolmaster and schoolmistress, and for the education by them of all the children in the workhouse under fifteen. And yet our authors can write : "The policy of the Central Authority at this date, in short, deliberately excluded any use of the workhouse for the curative, reformative, or educational treatment of any class whatsoever" ! (p. 82).

The only sense in which this sweeping indictment applies is the strictly limited one that the Central Authority has never regarded the workhouse as a training-school for able-bodied adults. Both the Majority and Minority sections of the late Commission 
believe that this class can be to some extent-how far is doubtful -treated on the same basis as the sick and immature; and if the recommendations of either are carried into effect there will be a real extension of the Principle of Curative Treatment to another class.

We have seen, then, that one of the "Principles of 1907 " belongs just as truly to 1834 . Let us now consider one of the "Principles of 1834 "-the Principle of Less Eligibility in its original and special application to the treatment of the able-bodied pauper. We shall find it present in 1907 not only in the policy of the Central Authority, but also, and notwithstanding all disguises, in the Report of the Minority. This Principle is stated on p. 228 of the 1834 Report in the following words : "The first and most essential of all conditions, a principle which we find universally admitted, even by those whose practice is at variance with it, is that his (i.e., the able-bodied pauper's) situation on the whole shall not be made really or apparently so eligible as the situation of the independent labourer of the lowest class." This does not mean that the relief given is to be inadequate, but that it is to be given under conditions such as will not tempt the independent "to quit the less eligible class of labourers and enter the more eligible class of paupers."

On pp. 261-3 the authors of English Poor-Law Policy suggest that the Central Authority has abandoned this Principle in respect to all but vagrants, but admit that there is no "explicit statement" to that effect (261-3). Since, however, the Central Authority is on trial only with regard to its explicit statements, that settles the question. The reference to the treatment of the able-bodied under the Unemployed Workmen Act is wholly misleading in dealing with the history of Poor-Law policy. The Act was created in order to get behind that policy, and its success in doing so has made of it a gigantic and admitted failure.

It is, indeed, inconceivable that any scheme for the relief of the able-bodied should be framed which is not, tacitly or avowedly, based upon the Principle of Less Eligibility. The pill may be sugared with eulogistic epithets, and gilded with the promise of lavish allowances; but not even a Socialist State could afford to offer to all comers a life of dependence which should be more eligible than one of independence. It is true that the Minority repudiate the Principle as "futile and barbarous in its inhumanity" (p. 358, E. P. L. Policy), and offer in its stead "full and honourable maintenance at the public expense" (Minority Report, p. 9216) ; but, still, it is there in their proposals, and there 
so definitely that they anticipate having to apply their new Principle of Compulsion to induce some at least of the unemployed to accept their hospitality. To show the struggle which has gone on in the minds of the Minority between their desire to conceal a Principle which they have done so much to make unpopular and their recognition of its necessity, it is necessary to quote at some length from the Report itself. On p. 1204 we find a description of the treatment proposed for the able-bodied unemployed : "For the young unmarried man it would probably be best to send him at once to a residential settlement in the country, where he would be free from the distractions of town life" (a delightful euphemism !). "But whether in town or country, it is essential to successful treatment that the training should take up the man's entire day. If he is not at a residential colony, he will be required to be in attendance at 6 a.m., as he would be if he were in employment; and as the day's training will need to be diversified, and must include organised recreation of various kinds, his obligatory attendance will usually be prolonged until eight or nine at night." After an enumeration of the advantages of this treatment comes a significant defence: ". . . it is not agreeable to the 'average sensual man' to surrender himself continuously to an ordered round of continuous training of any sort under hygienic conditions, with every faculty kept alert by varied stimuli, so as to produce the highest state of physical and mental efficiency of which he is capable. In short, maintenance under training, whilst more ' eligible' in every sense than starvation in idleness, is less agreeable than the ordinary industrial employment at wages, in one's own occupation, with freedom to spend or misspend one's wages and one's leisure as is desired," But what is this "less agreeable" but the "less eligible" of 1834 over again? To find a mode of assistance which shall be preferable to starvation while it is not preferable to independent work for wages has been the Principle actuating the Central Authority from the beginning, and in theory at least the Minority does not deviate from it. Whether in practice their plan would work out quite as they intend is another question. We think they under-estimate the power of the normal man to defend himself against unwelcome "stimuli"; it might be measured by his state of mind during a sermon, or-if he be unmusical-at an orchestral concert. He is quite capable of preserving an air of intelligence which covers an absolute blank within so long as he is warm and fairly comfortable.

But what about "the freedom to spend or misspend one's wages and one's leisure as is desired," which is to attract the men 
back into employment and away from the State training establishments? That it will be a very limited freedom appears when we turn the page. "So long as he commits no crime, and neglects none of his social obligations-so long as he does not fail to get lodging, food, and clothing for himself and his family-so long as his children are not found lacking medical attendance when ill, or underfed at school-so long, indeed, as neither he nor his family ask or require any form of Public Assistance, he will be free to live as he likes. But directly any of these things happen, it will be a condition that the husband and father, if certified as ablebodied, shall be in attendance at the Training Establishment to which he is assigned. If he is recalcitrant, he will be judicially committed to a Detention Colony."

But why should any man be "recalcitrant" to an offer of "full and honourable maintenance" unless it is to be accompanied by conditions which he does not like-i.e., which make it "less eligible" than his position, not only as an independent labourer, but as a man unable to maintain his family?

So far, then, we find that on examination two of the contrasted Principles of 1834 and 1907-perhaps the two most important-prove to be common to Poor-Law policy of both periods. We offer this result as an answer to a rhetorical statement of $\mathrm{Mr}$. Webb's in the Sociological Review for April, 1909. "For what the Royal Commission of 1905-9 has done, in its Majority Report no less than in that of the Minority, has been to destroy the much vaunted 'Principles of 1834,' to reveal the intellectual bankruptcy of the policy so long inculcated by the headquarters of the Charity Organisation Society, and to 'smash, pulverise, and destroy' the whole Poor-Law system” (p. 128).

The case against him is strengthened when we pass to the two remaining "Principles of 1834 "; they will take little space. The "Principle of National Uniformity" comes first, and it is, we are told, "in 1907, with one notable exception, in practice abandoned. Uniform national treatment is to-day obligatory with regard to one class only of destitute persons, the wayfarers or vagrants" (p. 258). In the sense that the Guardians do exercise a very wide discretion within the limits laid down by the Central Authority this is true (and just as true with respect to vagrants as to other classes), and it is the reason why-as we have already pointed out-Poor-Law history cannot be written from a study of official documents alone. But the argument, which proceeds by enumerating divergencies of practice with respect to the children and the sick, shows a hopeless confusion in the authors' minds 
between a Principle and the practice in which it is embodied, between a policy and the various methods of carrying it into effect. Given the policy (e.g.) of providing the best treatment for the sick, it is clear that it may be achieved in some places by building a special infirmary, in others by subsidising a voluntary institution. What remains desirable is that the Central Authority should impress a uniform policy upon the nation, and though it has not completely succeeded in doing this, it has never abandoned the attempt. And once more we need only go to the Minority Report itself to find the "Principle of Uniformity" invoked as part of their scheme of reform. In Chapter VIII., on Cost and Recovery (pp. 944-5), the writers deprecate the "lack of principle and uniformity" in the process of charge on and recovery from individuals of the cost of maintenance, and lay down as urgent "the adoption of some uniform principle, with regard to charging or not charging, throughout the whole of each service."

The third "Principle of 1834 " is said to be that of the "Workhouse System." "The workhouse system was recommended on the assumption that it was the only means by which the Principle of Less Eligibility could be enforced" (English Poor-Law Policy, p. 11). But in this sense the workhouse system is not a Principle at all; it is merely a mode of applying a Principle, one way amongst others of carrying out a given policy. There was indeed another principle as well as that of Less Eligibility in the minds of the Commission when they urged the use of the workhouse. It was not to act solely, or even mainly, as a test. It was intended also to put a stop to partial relief and the subsidising of wages, and so to carry out the principle upon which Friendly Societies base all their relief work. "On this point, as on many others, the independent labourers may be our best teachers. We have seen that in the administration of the funds of their friendly societies, they have long acted on the principle of rendering the condition of a person receiving their relief less eligible than that of an independent labourer. We have now to add that they also adopt and enforce most unrelentingly the principle that under no circumstances, and with no exceptions, shall any member of their societies receive benefit while earning anything for himself." This principle, which might be called the Principle of "All or Nothing," is ignored by the authors of English Poor-Law Policy, and we suspect is abandoned by them in their scheme of relief. We find no statement as to what policy is to be pursued with men who earn little but are not "unemployed"; but the inference 
is inevitable that it is to be one of subsidies from the various Committees who will be inspecting his family. If so, then another Principle should have been added to those of 1907, the Principle of Partial Relief or the Subsidising of Wages.

We now come to the "Principles of 1907." The most important, the Principle of Curative Treatment, we have found to be inherited from 1834. There remain the Principles of "Universal Provision " and of "Compulsion." The attempt to introduce the first of these into the sphere of relief is perhaps the most daring of all the proposals before us. "What is most strikingly new since 1834 in the policy of the Central Authority is the Principle of Universal Provision-that is, the provision by the State of particular services for all who will accept them, irrespective of 'destitution' or inability to provide the services independently" (p. 267).

The first thing we have to say in respect to this Principle is that it has no place in English Poor-Law policy of the present day. It is only by juggling with the term "Central Authority," which in this connection should be confined to the Poor-Law Division of the Local Government Board, and using it to include the Education Department and the Municipal Authorities, that the Principle has been forced into the argument at all. Vaccination, sanitation, education, parks, museums, and libraries-these are the instances adduced, and none of them have anything to do with Poor Relief. (The administration of vaccination by the Guardians is a purely accidental connection.) It is true that our authors make a desperate, but futile, attempt to show that the Local Government Board in the person of its President was forty years ago converted to the Principle of Universal Provision. In expatiating upon its advantages, they say: "It is this consideration which justifies the provision of municipal hospitals, and which, presumably, led the Central Authority of 1870 (under Mr. Goschen) to dwell upon the expediency of 'free medicine' to the poorer classes generally, as distinguished from actual paupers, and perfect accessibility to medical advice at all times under thorough organisation" (p. 267). We find this passage quoted no less than four times (pp. 123, 207, 219, 267), but always without reference to its context, which points out the grave objections to such a system, and the danger that it would break down the provision of medical aid by means of benefit and friendly societies.

The second point is that the authors are either not clear themselves what they mean by "Universal Provision," or are purposely confusing the issue. Sometimes it would seem that they mean 
merely that the State is to enter into business and provide services for those who would like to have them on payment; as,for instance, when they say on p. 295 that "the adoption of the Principle of Universal Provision does not imply or involve the gratuitousness of the service." In this sense the State would aim at being a Universal Provider on the same lines as Whiteley's, and the Principle is merely the Principle of Collectivism under a very thin disguise. But in other contexts it is quite clear that the provision is intended to be gratuitous ; as in the argument (p. 267) that in providing services "indiscriminately for everyone who is ready to accept them, the State does nothing to diminish the inequality of condition between the thrifty and the unthriftyfor it is a simple axiom that the addition of equals to unequals produces unequals-whilst it raises the standard of living of all." Payment by the thrifty would of course vitiate this ingenious argument; though indeed it is equally fallacious whether the services are to be rendered gratuitously or not, for it ignores the obvious fact that the services must be paid for in taxation by somebody, and that somebody will presumably be the thrifty and not the unthrifty. So that the only way to avoid differentiation would be to make the unthrifty pay for them and let the thrifty taxpayer have them free.

In this sense, then, the Principle is nothing but the beginning of Communism under no disguise at all, and how far it is meant ultimately to go is indicated on p. 270: "Once this corporate responsibility" (for the "universal maintenance of a definite minimum of civilised life") "is accepted, it becomes a question whether the universal provision of any necessary common service is not the most advantageous method of fulfilling such responsibility - a method which has, at any rate, the advantage of leaving unimpaired the salutary inequality between the thrifty and the unthrifty." This means, we take it, nothing less than the gratuitous provision of all the necessaries of life up to a definite minimum to all comers; and we do not think that the "thrifty" taxpayer will appreciate his share of the "salutary inequality," which means that he will pay both for himself and for the unthrifty.

With respect to the final Principle, that of "Compulsion," we need say little. There is no doubt that it has already been pushed much further, even in the sphere of Poor-Law policy, than could have been anticipated by the reformers of 1834 . It is possible that it may with advantage be extended still further in dealing with certain classes of mental and bodily disease. But if personal 
liberty is to be properly safeguarded, we shall have to go much more slowly in this direction than the Minority propose. We may turn against them here their own argument, which they maintain as against the Majority: "To compel, by law, able-bodied men and women to become paupers against their will; to force upon them a degrading status with the stigma of pauperism, when they do not even apply for public assistance, to compel them to come into an institution of the Destitution Authority when they ask only to be let alone, must, we think, in the absence of any judicial conviction of a specific offence against the law, be dismissed as politically out of the question." Strange to say, the Majority make no proposal for anything of the kind. It is the Minority which is going to instruct its Committees to give relief to a man's family whether he desires it or not, to "require" him thereupon to enter a Training Establishment, and if he refuses, to commit him to a Detention Colony. The Majority explain that they think such powers are unsuitable for a Public Assistance Authority, and that able-bodied persons guilty of carefully defined offences in the way of failure to maintain themselves and their families should be committed on a Justice's order to a Detention Colony under the Home Office.

So much for the two sets of Principles discovered or invented by the authors of English Poor-Law Policy and of the Minority Report. They resolve themselves into the Principles of Less Eligibility and Curative Treatment, both belonging equally to each period, but finding a different application under the different conditions of modern life; the Principle of National Uniformity, still an ideal to be aimed at, and recognised as such in the Minority Report; the Principle of Universal Provision, not yet recognised at all in the sphere of the Poor Law; and the Principle of Compulsion.

In the light of this analysis it is easy to meet the attack upon the Majority Report with which the book concludes. The accusation against it is that it abandons the Principles of 1834 and accepts those of 1907, and yet shows "a very definite trend backwards to the Principles of 1834 in a manner which seems to us calculated ingeniously to nullify the apparent repudiation, and in reality to leave the situation more confused than before." Our answer is that the confusion lies in the minds of those who have invented the artificial antithesis between the two sets of Principles. The Majority Report nowhere either tacitly or explicitly abandons the Principles of 1834, when those Principles are properly interpreted and understood. As another instance of 
misplaced ingenuity, we must quote the passage which is supposed to prove this abandonment: "Indeed, the Majority Report is in one place explicit in its repudiation of the 'Principles of 1834,' arguing that, whatever may have been their validity three-quarters of a century ago, they are no longer applicable even to the ablebodied" (p. 275). Now, what is the actual statement which finds this interpretation? "The administrators of the present Poor Law are in fact endeavouring to apply the rigid system of 1834 to a condition of affairs which it was never intended to meet. What is wanted is not to abolish the Poor Law, but to widen, strengthen, and humanise the Poor Law, so as to make it respond to a demand for a more considerate, elastic, and, so far as possible, curative treatment of the able-bodied." There is here, it will be seen, no word of the Principles of 1834 , but only of the system by which the earlier administrators sought to apply their Principles. The confusion surely lies in our authors' repeated failure to distinguish between a Principle or policy and the various systems or methods by which it may be carried out. If we may take an analogy from another department of administration, we might as well say that Scotland Yard gave up the policy of identifying recidivists when it abandoned the system of photography for that of finger-prints, or that a doctor gives up the attempt to cure his patient when he considers the time has come to stop a course of medicine and try a change of diet.

The Principles of the Majority Report are those of 1834 developed and applied to the changed conditions of 1907, and with the addition of the Principle of Compulsion within carefully restricted limits. With the Principle of Universal Provision in the sphere of relief the Majority have nothing to do in one way or another; the provision they make is always for a definitely limited section of society, for those who cannot provide for themselves. The Minority also, as we have shown, cannot really get away from the Principles of 1834 , though they make a great show of repudiation. But they can and do add their new Principle of Universal Provision, and whether that is a safe Principle upon which to administer relief we must leave it to our readers to judge.

Helen Bosanquet 